\title{
VARIOUS EDGE RESPONSE OF GROUND BEETLES IN EDGES UNDER NATURAL VERSUS ANTHROPOGENIC INFLUENCE: A META-ANALYSIS USING LIFE-HISTORY TRAITS
}

\author{
Tibor Magura ${ }^{1}$, GÁbor L. Lövei² ${ }^{2}$ and BÉla Tóthmérész ${ }^{3}$ \\ ${ }^{1}$ Department of Ecology, University of Debrecen, H-4032 Debrecen, Egyetem tér 1, Hungary \\ E-mail: maguratibor@gmail.com; https://orcid.org/0000-0002-9130-6122 \\ ${ }^{2}$ Department of Agroecology, Aarhus University, Flakkebjerg Research Centre \\ DK-4200 Slagelse, Denmark; E-mail: gabor.lovei@agro.au.dk; https://orcid.org/0000-0002-6467-9812 \\ ${ }^{3}$ MTA-DE Biodiversity and Ecosystem Services Research Group, University of Debrecen \\ H-4032 Debrecen, Egyetem tér 1, Hungary \\ E-mail: tothmerb@gmail.com; https://orcid.org/0000-0002-4766-7668
}

Edges are on the increase world-wide due to increasing fragmentation and loss of natural habitats. After formation, edges are maintained by various processes (natural vs. continued anthropogenic interventions: forestry, agriculture, urbanization) which influence the reaction of individual species to edge effects (history-based edge effect hypothesis), and this will be reflected in the diversity of assemblages. Diversity, however, is not the most appropriate indicator of the edge effect because species with different traits may respond differently to the edges. To further articulate the history-based edge effect hypothesis, we evaluated the edge effect on one of the most commonly used life-history traits, the feeding habit of ground beetles in forest edges. A meta-analysis based on 28 publications and 422 comparisons showed that natural vs. continued anthropogenic interventions as edgemaintaining processes reflected at the trait level. Abundance of herbivorous, omnivorous, and predatory ground beetle species were all higher in the natural edges than in the forest interiors, while no similar pattern occurred in edges with continued anthropogenic influence. These results suggest that structural and environmental changes at edges sustained by repeated anthropogenic influence adversely influencing ecosystem functions, with negative effects on ecosystem services like pest or weed control.

Keywords: edge effect, feeding habit, herbivorous, omnivorous, predatory.

\section{INTRODUCTION}

Ecological research traditionally sought to understand the working of major ecosystems as relatively large, homogeneous landscape elements. Starting with the 20th century there has been an increasing interest in studying transitional areas because it is realised that such areas between landscape units take on important control functions in flows of abiotic and biotic components of a spatial system (TURNer \& GARDNER 2015). Ecotone is a transitional zone between adjacent ecological systems, having a set of characteristics uniquely defined by space and time and by the strength of interactions between adjacent ecological systems (TURNER \& GARDNER 2015). Ecological systems include 
commonly described hierarchical entities such as demes, populations, communities, ecosystems, landscapes and biomes. Thus, ecotones can be defined at several hierarchical levels, from population to the biosphere; at any extension, from few centimetres to thousands of kilometres; and at both horizontal and vertical scales (CADENAsso et al. 2003b).

Habitat edge is a type of ecotone; it is interpreted on the meso-spatial scale and at the community level. At the border between two neighbouring habitats, environmental conditions are altered. Thus edges have abiotic attributes considerably different from either adjacent habitats (MurCiA 1995, EwERS \& Didнам 2006). Altered abiotic conditions and habitat characteristics on and near habitat edge have a direct impact on the spatio-temporal distribution and dynamics of many species. These changes in abundance and distribution, in turn, may modify species interactions (predation, brood parasitism, competition, herbivory, pollination and seed dispersal) in the habitat edges. These abiotic, direct and indirect biotic changes in edges form the "edge effect" (Murcia 1995). Because of their importance and ubiquity, ecological responses to the presence of habitat edges are one of the most extensively researched topics in ecology.

In the past three decades, edge research has focused on a wide range of organisms and on an increasingly diverse number of edge types, as well as on the mechanisms that can cause edge effects (Ries et al. 2004). Ries et al. (2004) have identified four fundamental mechanisms (ecological flows, access to spatially separated resources, resource mapping, and species interactions) that change species abundance patterns across habitat edges. Moreover, based primarily on resource distribution, RIES and SisK (2004) have presented a predictive model forecasting changes in abundance near edges for any species in any landscape. By using this predictive model, several edge responses for different species at various edge types were predictable, but clearly, some variability remained unexplained. These unexplained responses have made generalizations difficult and generated attempts to account for it (RIES \& SisK 2004). Edge orientation (edges in different positions relative to the sun; RIEs et al. 2004), temporal effects (at a variety of scales, including time of day, season, and year; Ries et al. 2004), habitat fragmentation effects (including patch size, isolation, quality of adjacent habitats, and landscape composition; RIEs et al. 2004, Hard et al. 2013), edge contrast (low vs. high; Ries et al. 2004, Peyras et al. 2013), magnitude of the edge effect (the difference between habitat patch and matrix; EwERs \& DidHAm 2006), species traits (habitat specialization, dispersal ability, time of activity, body size, and type of reproduction of species; Peyras et al. 2013, Carvajal-Cogollo \& Urbina-Cardona 2015) and habitat suitability (Peyras et al. 2013) were identified as the most important factors that may be responsible for the unexplained variation. 
The maintaining processes of habitat edges are also identified as important drivers of the edge effect (Strayer et al. 2003). Magura et al. (2017) conceptualised this as the "history-based edge effect hypothesis", assuming that dissimilar edge-maintaining processes (natural vs. continued anthropogenic interventions: forestry, agriculture, urbanization) will be reflected in the diversity of assemblages. A meta-analysis, focusing on one of the most common terrestrial habitat edges, forest edges, and on an abundant insect group, ground beetles (Coleoptera: Carabidae) shows that forest edges maintained by natural processes have significantly higher species richness than the forest interiors, while edges with continued anthropogenic influence do not have (MAGURA et al. 2017). Species richness, however, is not the most sensitive indicator of the edge effect, because species with different traits may respond differently to the same stimuli (KoIvula et al. 2004, Brigić et al. 2014, Magura 2017). Therefore, species with different traits should be analysed separately to evaluate their reaction to edges, otherwise basic ecological patterns may remain hidden (NAGY et al. 2018), and the biology of organisms cannot be neglected when trying to understand their ecological responses (Lövei \& Magura 2006). To further articulate the history-based edge effect hypothesis, we evaluated the edge effect using the feeding habit (as a life history trait) of ground beetles at differently maintained forest edges. More specifically, we predicted that forest edges maintained by natural processes have significantly more herbivorous, omnivorous, and predatory ground beetle individuals than the forest interiors, while edges with continued anthropogenic influence do not.

\section{MATERIAL AND METHODS}

\section{Study and data selection}

We performed a literature search in Web of Science ("All databases" option) for the period 1975-2015, using the following search term: TOPIC $=($ forest $)$ AND TOPIC $=($ edge OR margin) AND TOPIC $=\left(\right.$ carabid $\left.^{*}\right)$. The literature search was performed on 27 May 2016 at the University of Debrecen, Hungary. In addition, we also reviewed the papers on the subject for relevant publications that had remained undetected previously. To be included in the data matrix, a paper had to report data on carabid abundance in both forest interior and forest edge. From papers that studied carabids along transects, data from the interiormost location in the forest were used.

\section{Classification of edges based on their maintaining process}

Forest edges were classified based on their maintaining processes. Forest edges, whose neighbouring habitats (the forest interior and the adjacent grassland or meadows) were unmanaged (without fire damage, cutting, thinning, intensive grazing or mowing) for at least 50 years, were considered to be maintained by natural processes (succession). 
Forest edges created by forestry (clear-cutting, forest management), urbanization (forest patches embedded in, and adjacent to an urbanised area) and agriculture (the neighbouring habitat to the forest edge was cultivated, intensively grazed, mowed and/or regularly burned) were repeatedly disturbed and were considered as disturbance-maintained edges. Edges with anthropogenic disturbances were further divided into subgroups based on the type of human influence (forestry, urbanization, or agriculture). Forest edges maintained by a combination of these forces, and edges whose maintenance shifted between natural processes and anthropogenic disturbances over time were not included.

\section{Data analyses}

Ground beetles were categorized according to their feeding habit. Species that feed almost exclusively on seeds or other plant material were considered as herbivorous, while species mainly taking prey were considered predatory. Species using of live and/or dead prey, as well as plant or fungal material were considered omnivorous. The categorisation was made using information in LAROCHELLE (1990).

For each edge-to-interior comparison, the unbiased standardized mean difference (Hedges' $g$ ) as a common effect size was calculated between forest interior and forest edge:

$$
g=J \frac{\overline{X_{F}}-\overline{X_{E}}}{S_{\text {within }}}
$$

$$
S_{\text {within }}=\sqrt{\frac{\left(n_{F}-1\right) S_{F}^{2}+\left(n_{E}-1\right) S_{E}^{2}}{n_{F}+n_{E}-2}}
$$

and

$$
J=1-\frac{3}{4\left(n_{F}+n_{E}-2\right)-1},
$$

where $\bar{X}_{\mathrm{F}}$ and $\bar{X}_{\mathrm{E}}$ are the mean abundance of beetles in forest interior and forest edge, $n_{\mathrm{F}}$ and $n_{\mathrm{E}}$ are the sample sizes of the forest interior and forest edge, and $S_{\mathrm{F}}$ and $S_{\mathrm{E}}$ are their SDs.

Subgroup meta-analysis was used to determine whether the edge has an effect on ground beetle abundance according to forest edge maintenance (natural or types of anthropogenic influence). We estimated the overall effect and examined the effects of moderators (the type of edge maintaining process; type of anthropogenic influence) using a randomeffects model.

Meta-analyses are based on one of two statistical models, the fixed-effect model or the random-effects one (BorensteIn et al. 2009). A fixed-effect model assumes that there is one true effect size and that all differences in the observed effects are due to sampling error. A random-effects model, more plausibly also attributes the distribution of effect sizes to real differences among studies and do not assume sampling error as the only source of variability in effect sizes (Borenstein et al. 2009). We used the random-effects model, because studies were not expected to estimate a common effect size due to differences in study regions, locations, conditions, experimental setups and research methods in the individual studies. Several effect sizes for edge-to-interior abundance comparison were obtained from the same publication. To account for this, we included a publication-level random effect as a nesting factor into the model. The mean effect size was considered statistically significant when the $95 \%$ bootstrap confidence interval (calculated with 999 iterations) did not include zero. 
To describe heterogeneity, complementary measures of $Q$ and $I^{2}$ were calculated (BoRENSTEIN et al. 2009). $Q$ is the weighted sum of squares within a data set. For significant heterogeneity, it can be tested against the expected deviation assuming that all studies share a common effect size. $I^{2}$ measures the proportion of the observed variance that reflects real differences in effect size between studies. Total variance $\left(Q_{\text {total }}\right)$ was partitioned into within- $\left(Q_{\text {within }}\right)$ and between group $\left(Q_{\text {between }}\right)$ variances and these were tested for statistical significance (BorENSTEIN et al. 2009). Significant variance between groups $\left(Q_{\text {between }}\right)$ means that edge effect on abundance significantly differed according to the maintaining processes of edges. During the calculations, subgroups with less than five cases were excluded from analyses. Publication bias was tested using funnel plots and the Egger test (Borenstein et al. 2009). In the case of significant asymmetry, the trim and fill method was used (Duval \& Tweedie 2000). During the calculations, the MAd (version 0.8-2, Del Re \& Hoyt 2014) and metafor packages (version 1.9-9, VIEchtBAUER 2010) were used in R programming environment (version 3.4.3; R CoRe TеAм 2017).

\section{RESULTS}

The literature search yielded 204 publications; after applying the selection criteria, 53 papers were retained. Of these, mean abundance of herbivorous/omnivorous/predatory ground beetle species with standard deviations, and sample sizes for forest interiors and edges were recoverable from 28 publications (Appendix, Table S1). Eleven papers compared forest edges maintained by natural processes, and 17 papers ones by continued anthropogenic interventions to the respective forest interiors. Edges maintained by human influence were further grouped according to the activity type: agriculture (7 papers), forestry (8 papers), or urbanization (3 papers). A single study examined two types of human influence. In total, our meta-analyses were based on 422 separate edge-to-interior abundance comparisons (15 for herbivorous, 70 for omnivorous, and 337 for predatory species).

Data on the abundance of herbivorous species in edges maintained by human influence were few $(n=3)$; therefore, a subgroup meta-analysis could not be performed. The abundance of herbivorous species, however, was significantly higher in the edges maintained by natural processes than the interiors (Fig. 1a). No significant heterogeneity (Appendix, Table S2) was detected, but the Egger test indicated funnel plot asymmetry. The trim and fill procedure (adding 6 data points) did not change the significance of the overall effect (Appendix, Fig. S1a).

The abundance of omnivorous species was higher at edges maintained by natural processes than the respective forest interiors, while no similar pattern occurred in edges with continued anthropogenic influence (Fig. 1b), although the between-group variance $\left(Q_{\text {between }}\right)$ was not significant (Appendix, Table S2). Neither the total nor the unexplained heterogeneity was significant (Appendix, Table S2). In either type of anthropogenically disturbed edges (ag- 
(a)

Natural edges (12)

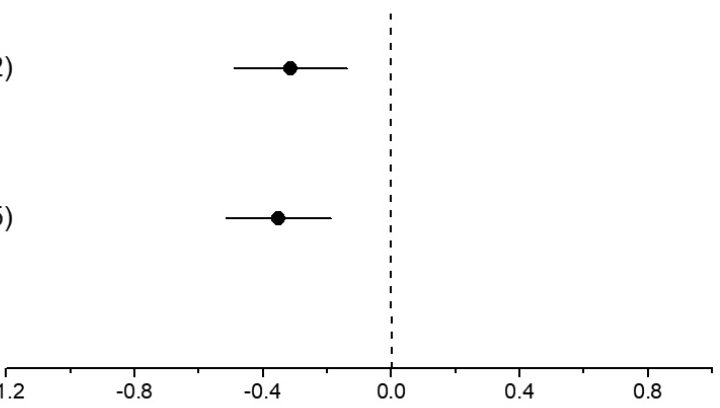

All edges (15)

(b)

Edges with natural processes (54)

Edges disturbed by forestry (8)

Edges disturbed by agriculture (6)

Edges with human influences (16)

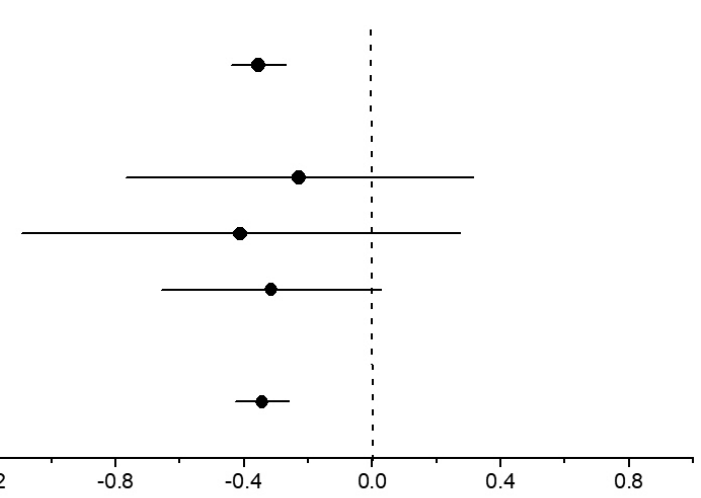

(c)

Edges with natural processes (227)

Edges disturbed by urbanization (13)

Edges disturbed by forestry (67)

Edges disturbed by agriculture (30)

Edges with human influences (110)
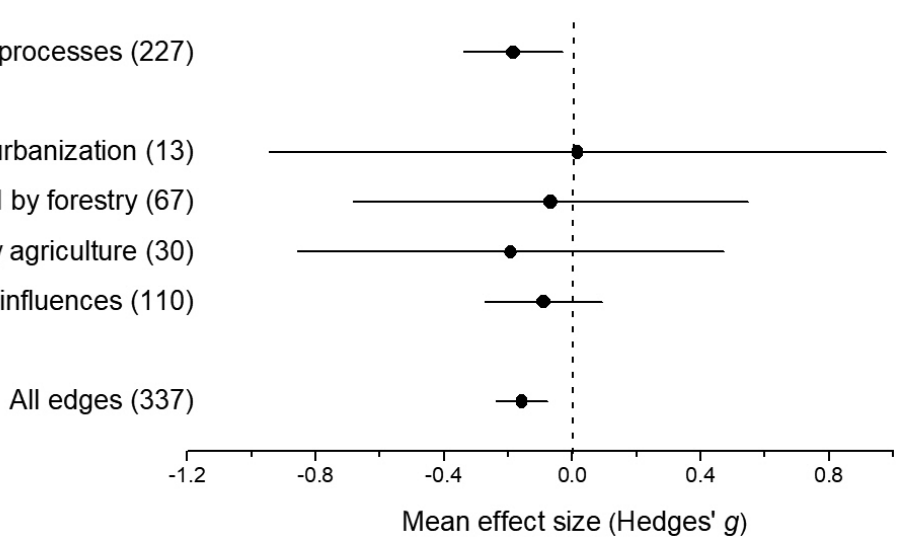

Fig. 1. Mean effect sizes of random-effect models (mean Hedges $g \pm 95 \%$ confidence interval) for the abundance of herbivorous (a), omnivorous (b), and predatory ground beetle species (c). Values in brackets refer to the number of species for whose abundance the mean effect size was calculated. A negative $g$ value means higher abundance in forest edges than interiors. The mean effect size was considered statistically significant if the $95 \%$ bootstrap confidence interval did not include zero. "Edges with human influences" represents data

from edges under anthropogenic influences (agriculture, forestry, or urbanization) 
riculture or forestry), the abundance of omnivorous species was not significantly different between edges vs. interiors (Fig. 1b), with no significant heterogeneity (Appendix, Table S2). Regression tests showed significant funnel plot asymmetries. The trim and fill method estimated 19 missing values, but adding these did not change the significance of the overall effect in the model (Appendix, Fig. S1b).

Forest edges maintained by natural processes had significantly higher abundances of predatory species than the forest interiors, while edges under continued anthropogenic influence showed no such difference (Fig. 1c), although the between group variance $\left(Q_{\text {between }}\right)$ was not significant (Appendix, Table S2). There was significant total and unexplained heterogeneity (Appendix, Table S2). In all types of edges maintained by continued anthropogenic interventions, the abundance of predatory species was not significantly different between edges and respective interiors (Fig. 1c). In this model, both the total and the unexplained heterogeneity were significant (Appendix, Table S2). Neither the classical nor the random-effects version of the Egger test revealed significant asymmetry in the funnel plot, indicating the absence of publication bias (Appendix, Fig. S1c).

\section{DISCUSSION}

Our study, evaluating the edge response of ground beetles with various feeding habits in differently maintained forest edges, allows a deeper insight into the history-based edge effect hypothesis of MaGura et al. (2017). Our results showed, that dissimilar maintaining processes (natural vs. continued anthropogenic interventions) of edges reflected not only at the community level (e.g. reflected by diversity, Magura et al. 2017), but also at the trait level. Herbivorous, omnivorous, and predatory ground beetle species showed similar trends; abundances were higher in natural edges than in the forest interiors, whilst no similar pattern at edges with continued anthropogenic disturbance was detectable. On par with our findings, Harper et al. (2015) concludes that the edge response is different at edges with natural disturbance (fire), than at edges with anthropogenic disturbance (forest harvesting). Based on our results, therefore, we propose to make a distinction between forest edges maintained by natural processes (mainly by succession), which are the "proper" edges and those maintained by repeated anthropogenic influence (agriculture, forestry, urbanization), which we suggest to call borders. Mechanisms and functions in edges controlled by natural processes are considerably different from anthropogenic disturbance-induced processes (MAGura et al. 2017).

The main cause of the difference of forest edges with different maintaining processes could arise from differences in structure. Forest edges main- 
tained by natural processes have a stratified horizontal structure: they have a shrub and sapling zone towards the forest interior, and a perennial herb layer towards the adjacent open habitat (Forman \& Godron 1986). Due to this physiognomy, natural edges have high habitat heterogeneity, and distinct environmental conditions which change at a modest magnitude (CADENAsso et al. 2003b). Habitat structure is an important factor in shaping the composition of ground beetle assemblages (structural heterogeneity hypothesis, BROsE 2003), as structurally complex vegetation offers microhabitats for resting, hibernation and oviposition, widens the food spectrum, and the chance of escape from natural enemies (MAGura 2002, Brose 2003). As a consequence, herbivorous, predatory and omnivorous species are all likely to be attracted to edges maintained by natural processes (CADENAsso et al. 2003a,b). In contrast, forest borders under anthropogenic influence are repetitively exposed to several kinds of direct disturbance by management operations, such as tillage, grazing, mowing, and anthropogenic fires. They also are exposed to indirect disturbance, including pesticide, herbicide and fertilizer drifts. At forest borders adjacent to intensively farmed fields, the high input of fertilizers and plant protection products have adverse effects on vegetation diversity and composition: weeds and generalist species become more common, habitat specialists strongly decline, causing homogenized vegetation, and reduced species diversity (Boutin \& Jobin 1998). Simplified habitat structure, and more widely fluctuating environmental conditions can also influence soil properties (including soil moisture, acidity and fertility), litter turnover, evapotranspiration, nutrient cycling and decomposition (HARPER et al. 2005). The repetitive disturbance prevents the development of stratified horizontal structure and reduces habitat heterogeneity at borders under human influence. Changes in vegetation structure and composition, microclimate and microhabitats in the borders under human influence are detrimental for species from the neighbouring habitats (Murcia 1995). Consequently, as our results showed, none of ground beetles with various feeding habits reached higher abundance at these human-influenced borders than in the respective adjoining habitats.

Individuals can disperse actively from the forest interior across the edge, and vice versa. If these individuals find appropriate conditions and microhabitats in forest edges, they may stay and even permanently settle down there. Therefore, forest edges can accumulate species from both adjoining habitats (MAgura et al. 2001, Harper et al. 2005). Similar dispersal of ground beetles between forests and neighbouring open-habitat across edges is well documented (Lacasella et al. 2015, Boetzl et al. 2016, Magura 2017, Magura \& Löver 2018). They may have important roles in ecosystem services, like the pest control by predatory forest species in adjacent agricultural fields (Roume et al. 2011). However, our results showed that the abundance of predatory and omnivorous ground beetles was not higher at forest borders under ag- 
ricultural influence compared to the forest interiors, assuming that dispersal or spillover of these beetles into neighbouring agricultural field is limited. In correspondence with our assumption, a recent study, using artificial sentinel prey, also indicated little of predator spillover from the native forest remnants to the cultivated matrix in Argentina (FerRAnte et al. 2017). It seems that the repeated anthropogenic interventions could have negative effect on ecosystem functions at edges, with negative consequences for ecosystem services like pest control.

Significant total and unexplained heterogeneity, and non-significant between group variances in the models underline that besides the maintaining processes of habitat edges, other inherent features of forest edges (size, isolation, type and quality of adjacent habitats, temporal effects, edge orientation, see Ries et al. 2004, Ewers \& Didham 2006) must also be considered in edge effect studies. Moreover, species with identical feeding habits may react differently to edge conditions depending on other traits. These species-level differences may be responsible for the remaining heterogeneity, suggesting that other species characteristics and traits (habitat specialization, dispersal ability, time of activity, body size, and type of reproduction) could be also important factors influencing edge response (RIEs et al. 2004).

Our finding that the edge response can be mediated by maintaining process of edges is based on ground beetles, which are at the consumer trophic level of the food web. Similar responses may be expected for organisms with a different trophic position, mobility, development type, life history or life span (see for butterflies, Pryke \& Samways 2003; for millipedes, Bogyó et al. 2015). A global meta-analysis incorporating all the above-mentioned variables would be challenging but very informative for testing the generality of our historybased edge effect hypothesis.

Acknowledgements - We are grateful to the Hungarian Academy of Sciences and the Hungarian Research Found (OTKA K-116639, OTKA K-131459, NKFI KH 126477) for supporting this research.

\section{REFERENCES}

Boetzl, F. A., Schneider, G. \& Krauss, J. (2016): Asymmetric carabid beetle spillover between calcareous grasslands and coniferous forests. - Journal of Insect Conservation 20: 49-57. https://doi.org/10.1007/s10841-015-9838-6

Bogyó, D., Magura, T., Nagy, D. D. \& Tóthmérész, B. (2015): Distribution of millipedes (Myriapoda, Diplopoda) along a forest interior - forest edge - grassland habitat complex. - ZooKeys 510: 181-195. https://doi.org/10.3897/zookeys.510.8657 
Borenstein, M., Hedges, L. V., Higgins, J. P. T. \& Rothstein, H. R. (2009): Introduction to meta-analysis. - John Wiley \& Sons Ltd., West Sussex, 452 pp.

Boutin, C. \& Jobin, B. (1998): Intensity of agricultural practices and effects on adjacent habitats. - Ecological Applications 8: 544-557. https://doi.org/10.1890/10510761(1998)008[0544:IOAPAE]2.0.CO;2

Brigić, A., Starčević, M., Hrašovec, B. \& Elek, Z. (2014): Old forest edges may promote the distribution of forest species in carabid assemblages (Coleoptera: Carabidae) in Croatian forests. - European Journal of Entomology 111: 715-725. https://doi.org/10.14411/ eje.2014.090

Brose, U. (2003): Bottom-up control of carabid beetle communities in early successional wetlands: Mediated by vegetation structure or plant diversity? - Oecologia 135: 407413. https://doi.org/10.1007/s00442-003-1222-7

Cadenasso, M. L., Pickett, S. T. A., Weathers, K. C., Bell, S. S., Benning, T. L., CarREIRo, M. M. \& Dawson, T. E. (2003a): An interdisciplinary and synthetic approach to ecological boundaries. - BioScience 53: 717-722. https://doi.org/10.1641/00063568(2003)053[0717:AIASAT]2.0.CO;2

Cadenasso, M. L., Pickett, S. T. A., Weathers, K. C. \& Jones, C. G. (2003b): A framework for a theory of ecological boundaries. - BioScience 53: 750-758. https://doi. org/10.1641/0006-3568(2003)053[0750:AFFATO]2.0.CO;2

Carvajal-Cogollo, J. E. \& Urbina-Cardona, N. (2015): Ecological grouping and edge effects in tropical dry forest: reptile-microenvironment relationships. - Biodiversity and Conservation, 24: 1109-1130. https://doi.org/10.1007/s10531-014-0845-9

Del Re, A. C. \& Hoyt, W. T. (2014): MAd: Meta-analysis with mean differences. https:// cran.r-project.org/web/packages/MAd/MAd.pdf

Duval, S. \& Tweedie, R. (2000): Trim and fill: A simple funnel-plot-based method of testing and adjusting for publication bias in meta-analysis. - Biometrics 56: 455-463. https:// doi.org/10.1111/j.0006-341X.2000.00455.x

Ewers, R. M. \& Didham, R. K. (2006): Continuous response functions for quantifying the strength of edge effects. - Journal of Applied Ecology 43: 527-536. https://doi. org/10.1111/j.1365-2664.2006.01151.x

Ferrante, M., GonzÁlez, E. \& Lövei, G. L. (2017): Predators do not spill over from forest fragments to maize fields in a landscape mosaic in central Argentina. - Ecology and Evolution 7: 7699-7707. https://doi.org/10.1002/ece3.3247

Forman, R. T. T. \& Godron, M. (1986): Landscape ecology. - Wiley \& Sons, New York, 620 pp.

Hardt, E., Pereira-Silva, E. F. L., Dos Santos, R. F., Tamashiro, J. Y., Ragazzi, S. \& Lins, D. B. D. S. (2013): The influence of natural and anthropogenic landscapes on edge effects. - Landscape and Urban Planning 120: 59-69. https://doi.org/10.1016/j.landurbplan.2013.08.014

Harper, K. A., Macdonald, S. E., Burton, P. J., Chen, J., Brosofske, K. D., Saunders, S. C., Euskirchen, E. S., Roberts, D., Jaiteh, M. S. \& Esseen, P. A. (2005): Edge influence on forest structure and composition in fragmented landscapes. - Conservation Biology 19: 768-782. https://doi.org/10.1111/j.1523-1739.2005.00045.x

Harper, K. A., Macdonald, S. E., Mayerhofer, M. S., Biswas, S. R., Esseen, P.-A., Hylander, K., Stewart, K. J., Mallik, A. U., Drapeau, P., Jonsson, B.-G., Lesieur, D., Kouki, J. \& Bergeron, Y. (2015): Edge influence on vegetation at natural and anthropogenic edges of boreal forests in Canada and Fennoscandia. - Journal of Ecology 103: 550-562. https://doi.org/10.1111/1365-2745.12398 
Koivula, M., HyyryläInen, V. \& Soininen, E. (2004): Carabid beetles (Coleoptera: Carabidae) at forest-farmland edges in southern Finland. - Journal of Insect Conservation 8: 297-309. https://doi.org/10.1007/s10841-004-0296-9

Lacasella, F., Gratton, C., De Felici, S., Isaia, M., Zapparoli, M., Marta, S. \& Sbordoni, V. (2015): Asymmetrical responses of forest and "beyond edge" arthropod communities across a forest-grassland ecotone. - Biodiversity and Conservation 24: 447-465. https://doi.org/10.1007/s10531-014-0825-0

Larochelle, A. (1990): The food of the carabid beetles (Coleoptera: Carabidae, including Cicindelinae). - Association des entomologistes amateurs du Québec, Québec, 132 pp.

Lövei, G. L. \& MAgura, T. (2006): Body size changes in ground beetle assemblages - a reanalysis of Braun et al. (2004)'s data. - Ecological Entomology 31: 411-414. https://doi. org/10.1111/j.1365-2311.2006.00794.x

Magura, T. (2002): Carabids and forest edge: Spatial pattern and edge effect. - Forest Ecology and Management 157: 23-37. https://doi.org/10.1016/S0378-1127(00)00654-X

MAgurA, T. (2017): Ignoring functional and phylogenetic features masks the edge influence on ground beetle diversity across forest-grassland gradient. - Forest Ecology and Management 384: 371-377. https://doi.org/10.1016/j.foreco.2016.10.056

Magura, T. \& LöveI, G. L. (2018) Environmental filtering is the main assembly rule of ground beetles in the forest and its edge but not in the adjacent grassland. - Insect Science 26(1): 154-163. https://doi.org/10.1111/1744-7917.12504

Magura, T., Lövei, G. L. \& Tóthmérész, B. (2017): Edge responses are different in edges under natural versus anthropogenic influence: a meta-analysis using ground beetles. - Ecology and Evolution 7: 1009-1017. https://doi.org/10.1002/ece3.2722

Magura, T., Tóthmérész, B. \& Molnár, T. (2001): Forest edge and diversity: carabids along forest-grassland transects. - Biodiversity and Conservation 10: 287-300. https:/doi. org/10.1023/A:1008967230493

Murcia, C. (1995): Edge effects in fragmented forests: implications for conservation. - Trends in Ecology and Evolution 10: 58-62. https://doi.org/10.1016/S0169-5347(00)88977-6

Nagy, D. D., Magura, T., Horváth, R., Debnár, Z. \& Tóthmérész, B. (2018): Arthropod assemblages and functional responses along an urbanization gradient: A trait-based multi-taxa approach. - Urban Forestry \& Urban Greening 30: 157-168. https://doi. org/10.1016/j.ufug.2018.01.002

Peyras, M., Vespa, N. I., Belloce, M. I. \& Zurita, G. A. (2013): Quantifying edge effects: the role of habitat contrast and species specialization. - Journal of Insect Conservation 17: 807-820. https://doi.org/10.1007/s10841-013-9563-y

PRYKe, S. R. \& SAMwAYs, M. J. (2003): Quality of remnant indigenous grassland linkages for adult butterflies (Lepidoptera) in an afforested African landscape. - Biodiversity and Conservation 12: 1985-2004. https://doi.org/10.1023/A:1024103527611

R Core TeAm (2017): R: A language and environment for statistical computing. - R Foundation for Statistical Computing, Vienna, $2630 \mathrm{pp}$.

Ries, L., Fletcher, R. J., Battin, J. \& Sisk, T. D. (2004): Ecological responses to habitat edges: Mechanisms, models, and variability explained. - Annual Review of Ecology Evolution and Systematics 35: 491-522. https://doi.org/10.1146/annurev.ecolsys.35.112202.130148

RiEs, L. \& Sisk, T. D. (2004): A predictive model of edge effects. - Ecology 85: 2917-2926. https://doi.org/10.1890/03-8021

Roume, A., Deconchat, M., Raison, L., Balent, G. \& Ouin, A. (2011): Edge effects on ground beetles at the woodlot-field interface are short-range and asymmetrical. - Agricultural and Forest Entomology 13: 395-403. https://doi.org/10.1111/j.1461-9563.2011.00534.x 
Strayer, D. L., Power, M. E., Fagan, W. F., Pickett, S. T. A. \& Belnap, J. (2003): A classification of ecological boundaries. - BioScience 53: 723-729. https://doi.org/10.1641/00063568(2003)053[0723:ACOEB]2.0.CO;2

Turner, M. G. \& Gardner (2015): Landscape ecology in theory and practice. Pattern and process. - Springer, New York, 482 pp.

Viechtbauer, W. (2010): Conducting meta-analyses in R with the metafor package. - Journal of Statistical Software 36: 1-48. https://doi.org/10.18637/jss.v036.i03

Received July 25, 2018, accepted September 1, 2018, published November 22, 2019

\section{APPENDIX}

Table S1. Publications used in the meta-analyses, which reported mean values of abundances, standard deviation, and sample size for both the forest interior and the forest edge.

\begin{tabular}{|c|c|c|c|}
\hline Edge type & $\begin{array}{l}\text { Human dis- } \\
\text { turbance }\end{array}$ & $\begin{array}{l}\text { Feeding type of the studied } \\
\text { species }\end{array}$ & Reference \\
\hline Natural & none & $\begin{array}{l}\text { herbivorous, omnivorous, } \\
\text { predatory }\end{array}$ & ELEK \& TóthMÉRÉSz 2010 \\
\hline Natural & none & $\begin{array}{l}\text { herbivorous, omnivorous, } \\
\text { predatory }\end{array}$ & LACASELLA et al. 2015 \\
\hline Natural & none & omnivorous, predatory & Magura 2002 \\
\hline Natural & none & omnivorous, predatory & MAGURA \& TóTHMÉRÉSz 1997 \\
\hline Natural & none & omnivorous, predatory & MAGURA \& TóTHMÉRÉSZ 1998 \\
\hline Natural & none & $\begin{array}{l}\text { herbivorous, omnivorous, } \\
\text { predatory }\end{array}$ & MAGURA et al. 2000 \\
\hline Natural & none & $\begin{array}{l}\text { herbivorous, omnivorous, } \\
\text { predatory }\end{array}$ & MAGURA et al. 2001 \\
\hline Natural & none & omnivorous, predatory & MAGURA et al. 2002 \\
\hline Natural & none & $\begin{array}{l}\text { herbivorous, omnivorous, } \\
\text { predatory }\end{array}$ & MÁtнÉ 2006 \\
\hline Natural & none & $\begin{array}{l}\text { herbivorous, omnivorous, } \\
\text { predatory }\end{array}$ & MolnÁr et al. 2001 \\
\hline Natural & none & $\begin{array}{l}\text { herbivorous, omnivorous, } \\
\text { predatory }\end{array}$ & TótHMÉRÉsz et al. 2014 \\
\hline Disturbed & agriculture & predatory & BedFord \& Usher 1994 \\
\hline Disturbed & agriculture & predatory & EWERs 2008 \\
\hline Disturbed & agriculture & predatory & Kagawa \& MaEto 2009 \\
\hline Disturbed & agriculture & omnivorous, predatory & Kagawa \& Maeto 2014 \\
\hline Disturbed & agriculture & predatory & SKLODOWSKI 1999 \\
\hline Disturbed & agriculture & omnivorous, predatory & TABOADA et al. 2004 \\
\hline
\end{tabular}


Table S1 (continued)

\begin{tabular}{|c|c|c|c|}
\hline Edge type & $\begin{array}{l}\text { Human dis- } \\
\text { turbance }\end{array}$ & $\begin{array}{l}\text { Feeding type of the studied } \\
\text { species }\end{array}$ & Reference \\
\hline Disturbed & agriculture & predatory & Yu et al. 2007 \\
\hline Disturbed & forestry & predatory & Gaublomme et al. 2013 \\
\hline Disturbed & forestry & omnivorous, predatory & Halaj et al. 2008 \\
\hline Disturbed & forestry & predatory & Heliölä et al. 2001 \\
\hline Disturbed & forestry & predatory & Lemieux \& Lindgren 2004 \\
\hline Disturbed & forestry & predatory & Phillips et al. 2006 \\
\hline Disturbed & forestry & omnivorous, predatory & SPENCE et al. 1996 \\
\hline Disturbed & forestry & $\begin{array}{l}\text { herbivorous, omnivorous, } \\
\text { predatory }\end{array}$ & ULySHEN et al. 2006 \\
\hline Disturbed & forestry & predatory & Yu et al. 2009 \\
\hline Disturbed & urbanization & omnivorous, predatory & Gaublomme et al. 2008 \\
\hline Disturbed & urbanization & predatory & Gaublomme et al. 2013 \\
\hline Disturbed & urbanization & omnivorous, predatory & SILVERMAN et al. 2008 \\
\hline
\end{tabular}




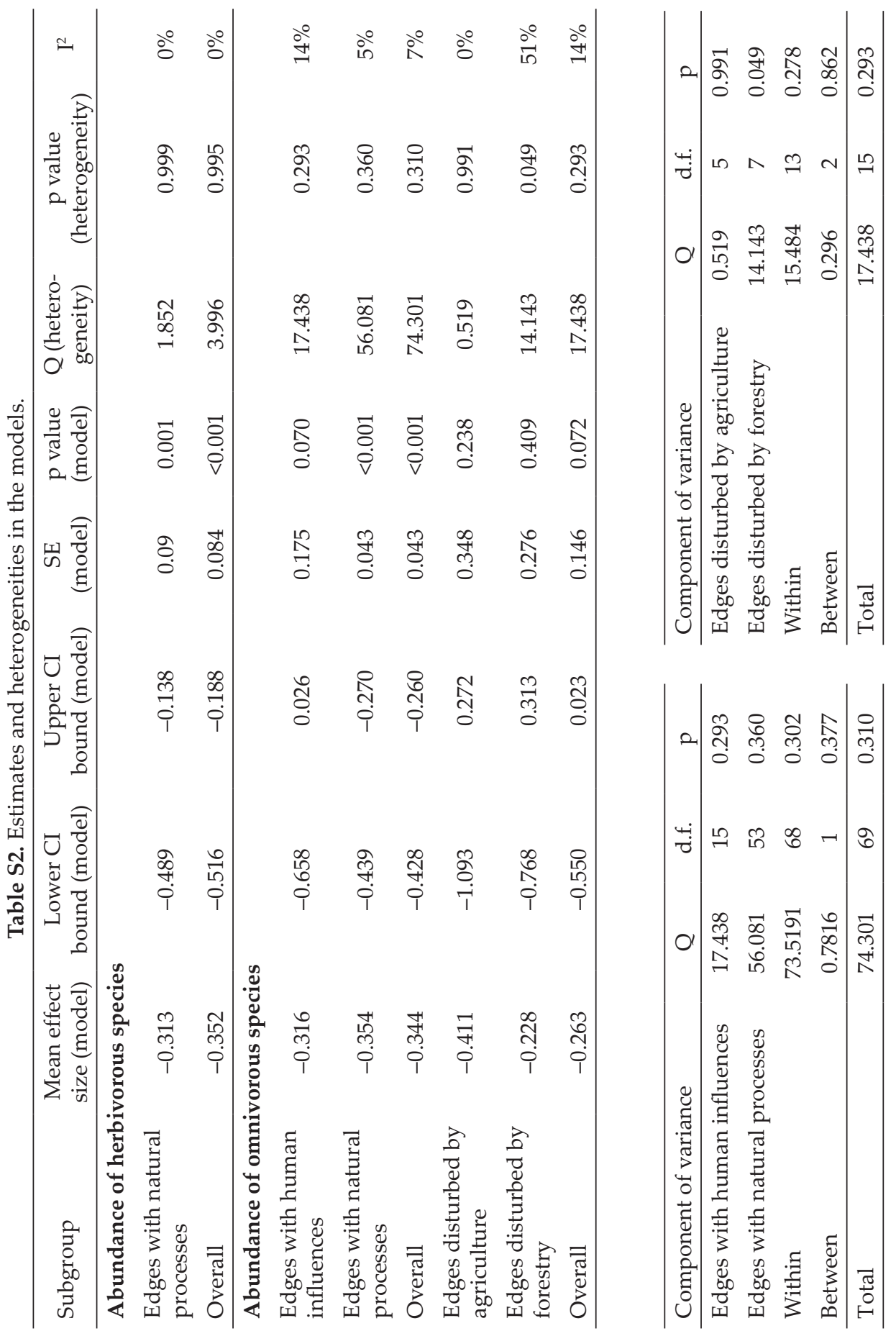




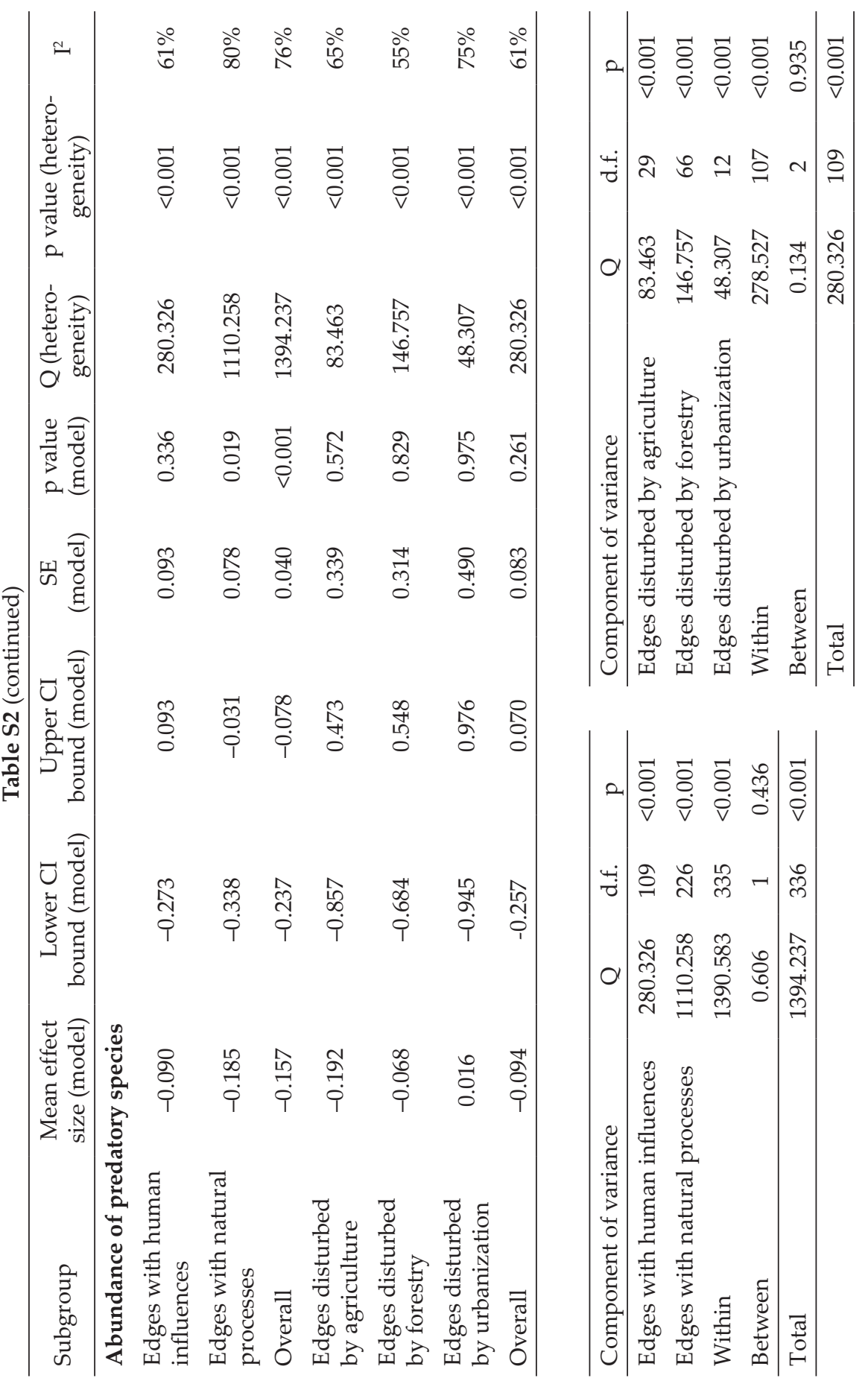


Figure S1. Funnel plots of the tested variables with missing studies (empty circles), regression tests for funnel plot asymmetry, and model results after trim and fill for the abundance of herbivorous (A), omnivorous (B), and predatory ground beetle species (C)

A

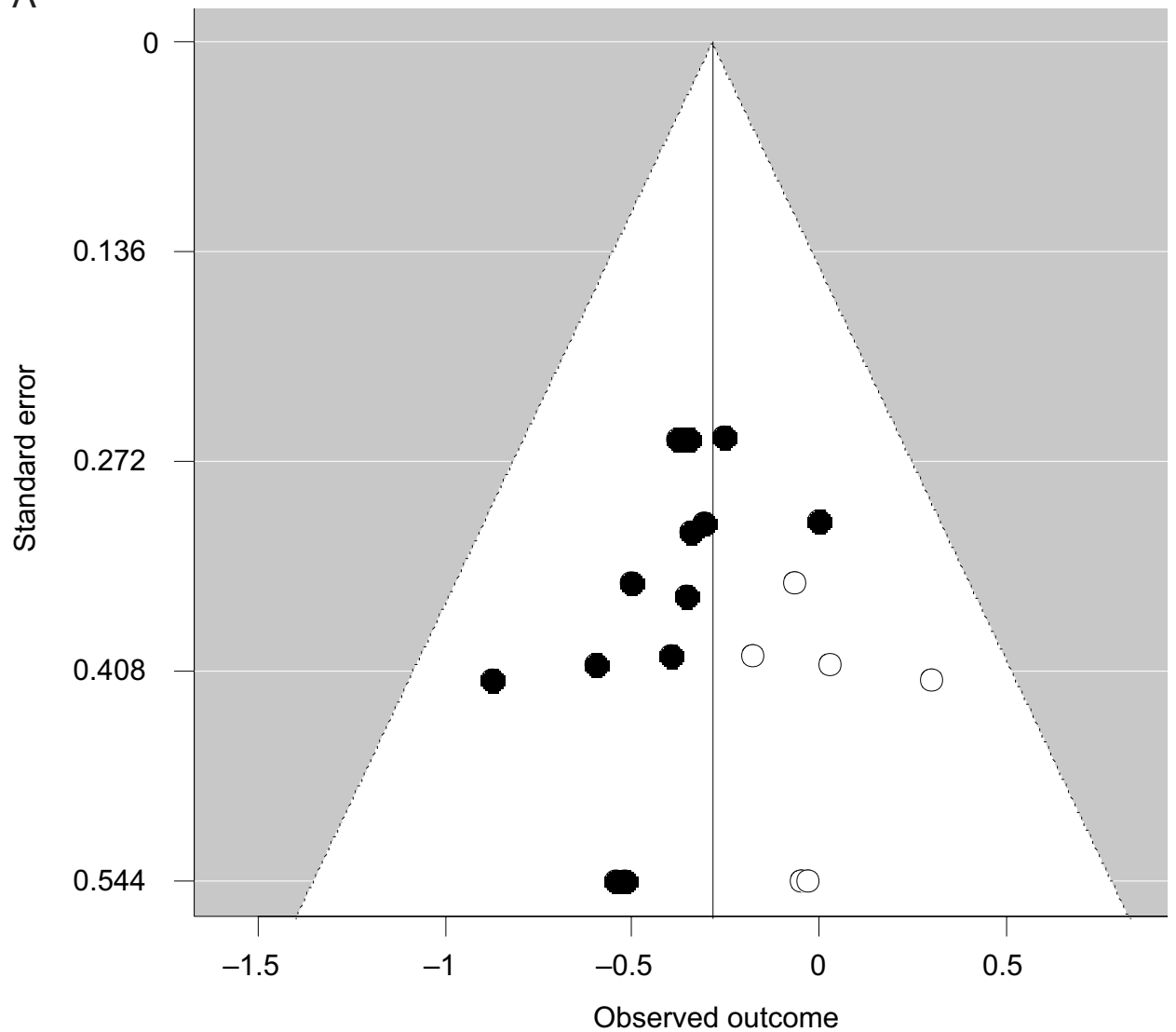

Regression Test for Funnel Plot Asymmetry

model: weighted regression with multiplicative dispersion

predictor: standard error

test for funnel plot asymmetry: $\mathrm{t}=-2.4181, \mathrm{df}=13, \mathrm{p}=0.0310$

model: mixed-effects meta-regression model

predictor: standard error

test for funnel plot asymmetry: $\mathrm{z}=-1.1134, \mathrm{p}=0.2655$

Model Results after Trim and Fill:

Estimated number of missing studies on the right side: $6(\mathrm{SE}=2.4826)$

$\begin{array}{ccccc}\text { Estimate Hedges } g & \text { Lower bound } & \text { Upper bound } & \text { Std. Error } & p \text { value } \\ -0.2859 & -0.4336 & -0.1381 & 0.0754 & 0.0001\end{array}$




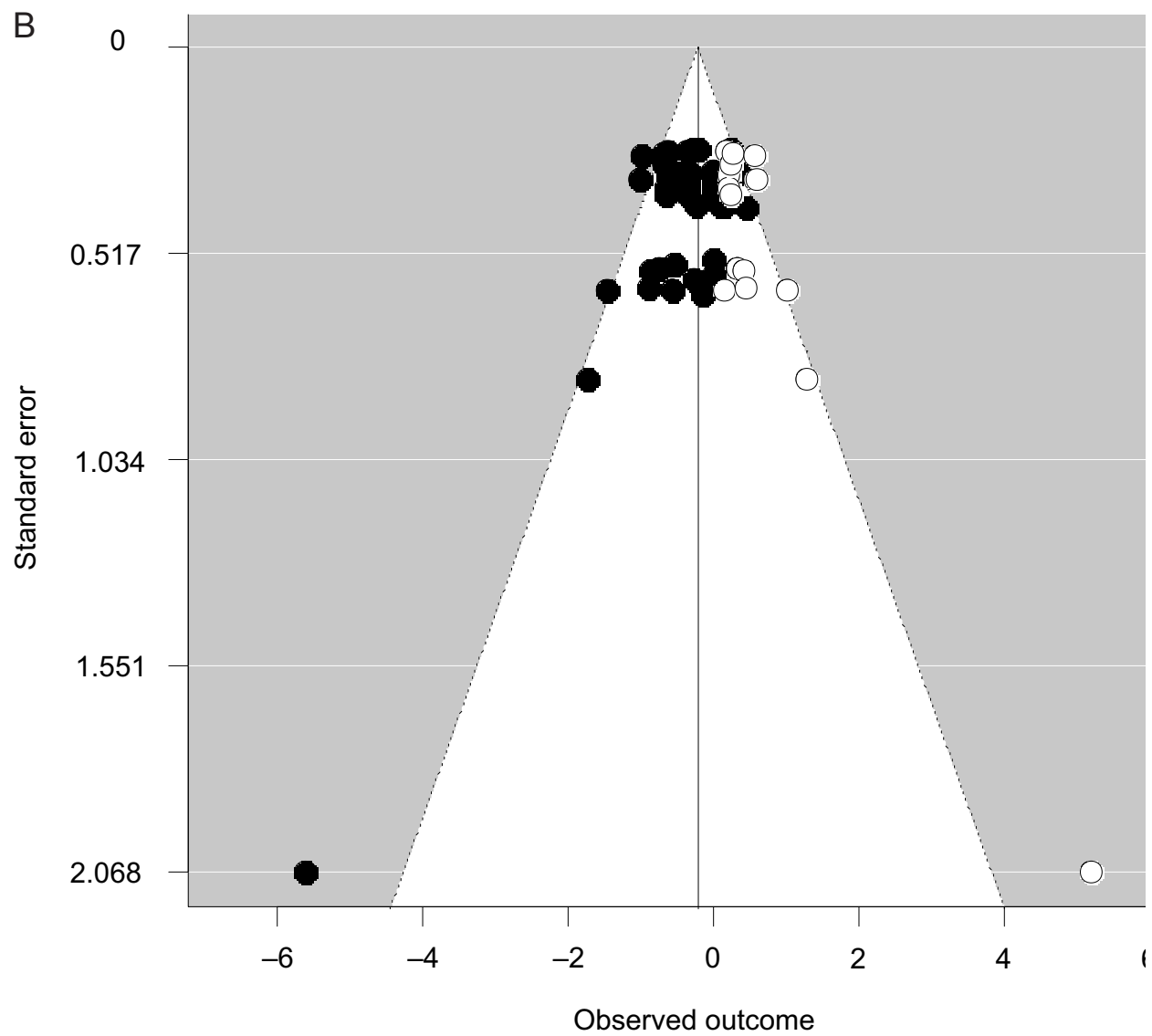

Regression Test for Funnel Plot Asymmetry model: weighted regression with multiplicative dispersion predictor: standard error test for funnel plot asymmetry: $\mathrm{t}=-2.4469, \mathrm{df}=68, \mathrm{p}=0.0170$ model: mixed-effects meta-regression model predictor: standard error test for funnel plot asymmetry: $\mathrm{z}=-2.4609, \mathrm{p}=0.0139$

Model Results after Trim and Fill:

Estimated number of missing studies on the right side: 19 (SE = 5.4397)

$\begin{array}{ccccc}\text { Estimate Hedges } g & \text { Lower bound } & \text { Upper bound } & \text { Std. Error } & p \text { value } \\ -0.2139 & -0.3051 & -0.1226 & 0.0466 & <0.0001\end{array}$




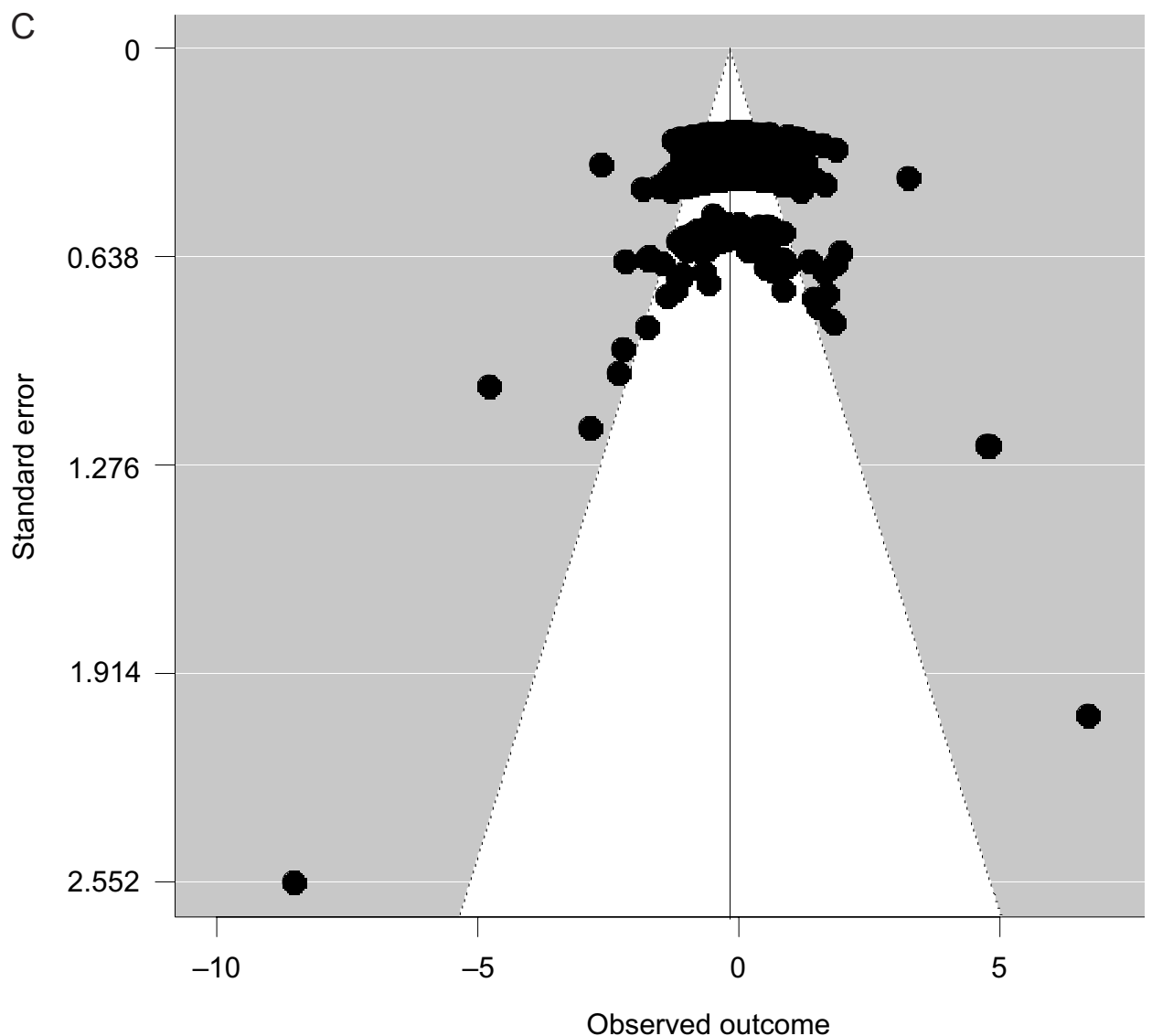

Regression Test for Funnel Plot Asymmetry model: weighted regression with multiplicative dispersion predictor: standard error test for funnel plot asymmetry: $t=0.7982, d f=335, p=0.4253$ model: mixed-effects meta-regression model predictor: standard error test for funnel plot asymmetry: $\mathrm{z}=0.5542, \mathrm{p}=0.5794$ 